Journal of Computer Science 6 (12): 1499-1504, 2010

ISSN 1549-3636

(C) 2010 Science Publications

\title{
Hybrid Auditory Based Interaction Framework for Driver Assistance System
}

\author{
Dalbir Singh \\ Center of Computer Science, Faculty of Information Science and Technology, \\ National University of Malaysia, 43600 Bangi, Selangor, Malaysia
}

\begin{abstract}
Problem statement: The rapid development of Driver Assistance System (DAS) provides drivers with radically enhanced information and functionality. The nature of the current DAS requires a complex human-machine interaction which is distracting and may increase the risk of road accidents. The interaction between the driver and DAS should aid the driving process without interfering with safety and ease of vehicle operation. Speech based interaction mechanisms employed are not sufficiently robust to deal with the distraction and noise present in the interior environment of the vehicle. Approach: Thus, suitable hybrid earcon/auditory icon design principles for DAS are developed. These interfaces are investigated in driving simulators in-order to test their durability and robustness. Several evaluation parameters will be applied. This will ensure the driving-related information from the DAS was delivered to the driver without affecting the overall driving process. Results: This study produces auditory design principles for information mapping (visual into nonspeech based interaction) and presentation framework was produced. It outlines representation architecture that enables concurrent auditory driving related information to be transmitted from four different sources in the vehicle's interior environment. It outlines a set of hybrid design principles that integrates auditory icons with earcons to map and present real-time driving related data from a visual to a non-speech auditory interface. Conclusion/Recommendations: The major contribution of this research project takes a genuine approach by considering the entire DAS (safety, navigation and entertainment subsystem). It proposes hybrid representation strategy based on the cognitive availability of the driver and cognitive workload. It was a significant discovery that aid future DAS auditory interaction design.
\end{abstract}

Key words: Earcon, hybrid, auditory icon, Driver Assistance System (DAS), synthetic speech, hierarchical architecture, earcon recognition, synchronous, psychoacoustics basis

\section{INTRODUCTION}

Currently, most of the driver assistance systems are derived from a visual-based interaction channel which displays complex information at a high rate (Staubach, 2009). As this requires a high visual processing capability, the driver's attention to the driving task is considerably reduced. Hence, there is a tendency for information to be misread as the driver's attention ceases and is not focused at the right place due to visual information overload. Moreover, these driver assistance systems increase the driver's reaction time to detect an event or incident and reduce the view of the road whilst driving. The in-vehicle environment becomes information-intensive where the visual channel is overloaded, hence unnecessarily jeopardizing the driver's and the passenger's safety (Mohamad et al., 2010).

Auditory (speech and non-speech) based interaction for driver assistance system is known to reduce the reaction time towards event detection and poses lesser danger to the driver (Cao et al., 2010). Improper application of synthetic speech based interaction for driver assistance system can have hazardous implications (Winters and Pisoni, 2006). This is because synthetic speech-based interaction poses high cognitive load on the driver's short term memory (auditory-speech processing capabilities). The use of synthetic speech may also be annoying for some driver and loses its prosodic information. Furthermore, the driver is loaded with other incoming speech-based interactions from the different types of driver assistance system while driving. The driver assistance system sometimes requires the driver to perform synchronous interactions with the vehicle's control mechanisms (Cao et al., 2010). The cognitive ability of the driver is reduced, especially in a demanding driving situation (Winters and Pisoni, 2006). Since the driver's distraction becomes a significant problem, the humanmachine interface needs to be designed as efficiently as 
2 possible. These driver assistance systems must function without decreasing safety as well as ease the overall driving process (Staubach, 2009).

Auditory based interaction research issues: In this research project, non speech based interaction architecture is proposed to complement the existing visual based interface. It is an alternative to synthetic speech based interaction for driver assistance system (Edlund et al., 2008). It integrates the attributes of auditory icons with earcons. This study discusses the research issues on earcon and auditory icon's interaction and design principles. These research issues must be borne in mind when creating auditory interaction mechanism for DAS (Fastrez and Haué, 2008). As nothing can be done about them; interfaces must be designed around those problems.

Earcon and auditory icon design principles assessment: Earcons and auditory icons have an edge over each other in certain conditions and that a hybrid of both might be the best for in-vehicle environment (Sodnik et al., 2008). In some circumstances, earcons might be best because of the structure manipulation, especially if there is no real-world equivalent of what the sounds are representing. Indeed, there may be some circumstances where the natural sounds of auditory icons can be manipulated to give the architecture of earcons. In our daily life, there is a continuum of sounds from the literal everyday sounds of auditory icons to the abstract sounds of earcons. The earcon will be heard more as a whole source and the sensitivity of the earcon moves more towards the figurative side of the range. Therefore, earcons and auditory icons are not necessarily different in certain cases. Both have advantages and disadvantages but these can be maximized/minimized by looking at the properties of each one of them (Sodnik et al., 2008). This research project will attempt to look more closely at the properties of earcons because, as yet, little is known about them for DAS applied in-vehicle environment.

Therefore, some clear experiments to test the usability of the earcons for the DAS applied in-vehicle environment are needed as a set of guidelines to help designers build effective auditory based interaction (Sodnik et al., 2008). The work described in this research project attempts to deal with these problems. Earcons are experimentally tested for in-vehicle environment and from the results, a set of strategies are created to help earcons design principles for DAS. In the work on earcons and auditory icons, little indication is given as to where and when sounds should be used in the DAS's interface. It proposes that they should be used in ways suggested by the common Human Machine Interaction principles but in a DAS interface, certain modification is needed. One essential step forward would be to have a method to find where; when and how sound applied to the DAS's interface would be useful. This research project proposes such a method.

Recognizing and memorizing earcons/auditory icons: The application of the characteristics of auditory based interaction requires a strong psychoacoustics basis. An important factor in the usability of earcons is its ability to recognizing and memorizing earcons/auditory icons (Garzonis et al., 2009). Structured sequences of sounds should be easily recognized and remembered as that will aid the user's memory. With the inheritance features, there is a unique parameter of attribute to remember at each level, thus making group earcons simpler to remember. Initially, there will be much to learn but later extensions will be simple. Group earcons seems to be a suitable mechanism for representing hierarchical architecture such as menus or errors (Smith et al., 2004). Group earcons could provide auditory clues about where the user's location is in the hierarchy, without adding to the visual information present. Unfortunately, previous research in this area did not realize a system of earcons and perform experiments to see how effective they were: Their usefulness is unknown.

Earcons are built on different parameters and this is the most important mechanism for grouping sounds into sources of grouping. It has been suggested to keep the sound used from the same attribute and in the same level because listeners can detect distinction between groups of sounds if all the attributes in one sound are at a different level from the other (Garzonis et al., 2009). Besides that, loudness sensitivity is crucial as different loudness is used to make a distinction among earcons for in-vehicle environment. Earcons have certain benefits over auditory icons because earcons have a more organized configuration. This may reduce the learning time and the cognitive load, but have not been tested. Auditory icons can be easily distinguished as is based on real sounds and linked by using a semantic connection to the objects they symbolize. Earcons are absolutely abstract, in relationship to the object that it represents (Sodnik et al., 2008). This causes the link to actions or objects within an interaction to be more difficult. Another earcon mapping and cognitive issue is that information mappings for a sound may be different and so the meaning of an auditory icon for in-vehicle environment would have to be learned (like an earcon) (Hoggan et al., 2009). Problems of uncertainty can occur when natural sounds are taken 3 out of the natural 
environment and placed in an in-vehicle environment. Earcons have a built-in architecture that can easily be edited. As auditory icons are only just beginning to adopt this (Yalla and Walker, 2008) building structures with them at present is difficult. An important step will be to test a DAS that uses earcons to discover their advantages and disadvantages. A major part of this research project is to do just this and find out how effective earcons are for DAS (in-vehicle environment).

DAS navigational and notification guidance: For navigational guidance purpose, 2 basic auditory icons were used as the base sound in the earcons. They indicate the left and right turning. The subjects were exposed with these auditory icons before the driving simulator experiments. 4 sets of different earcon design principles were tested on different driving routes. These designs were derived from previous research works and suited for DAS's interaction purpose (McGookin and Brewster, 2004). The intensity (loudness) of the auditory icons was increased to indicate the distance of a particular turning as illustrated in Fig. 1 and 2 .

Set 1: In set 1, the amplitude of the earcon increases as an indication toward higher level of notification. This is the simplest design principles employed in these set of earcons.

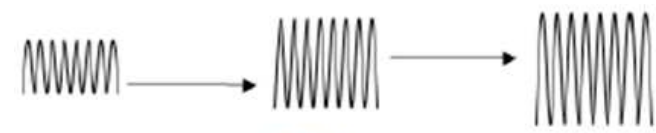

Increasing intensity of the base earcon but fixed length

Fig. 1: Set 1 earcon design architecture

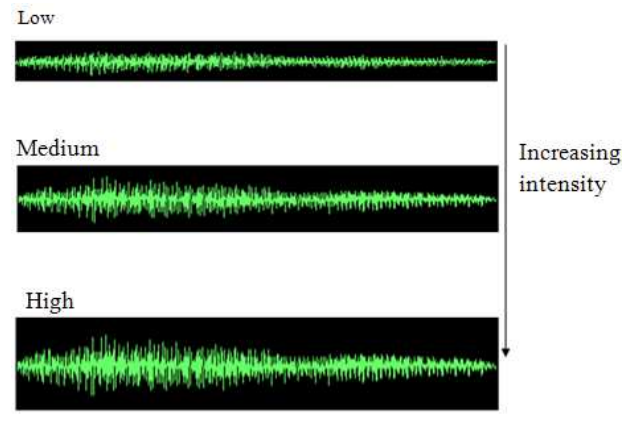

Fig. 2: Set 1 earcon sample waveform

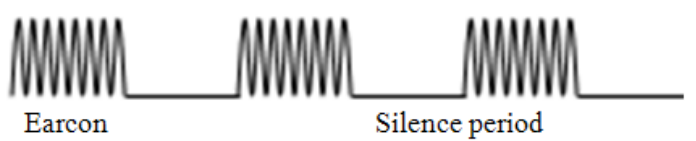

Fig. 3: Set 2 earcon design architecture

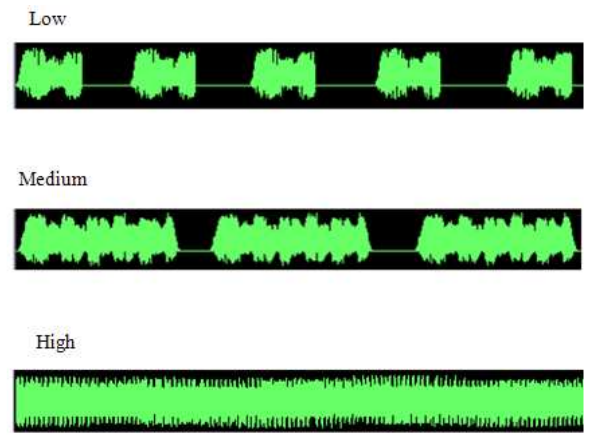

Fig. 4: Set 2 earcon sample waveform

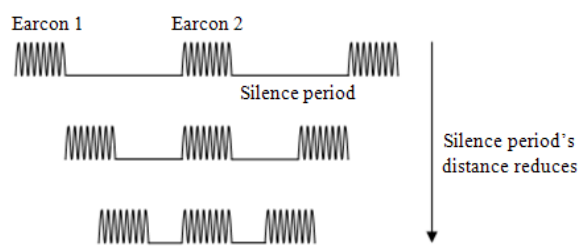

Fig. 5: Set 3 earcon design architecture
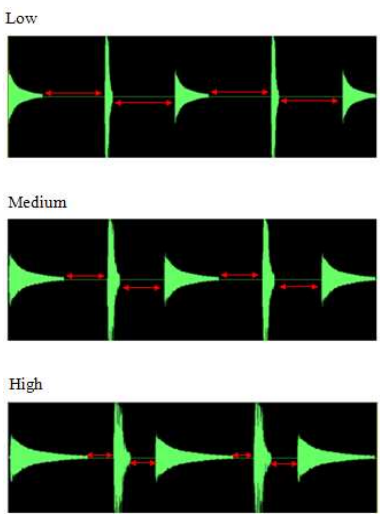

Fig. 6: Set 3 earcon sample waveform

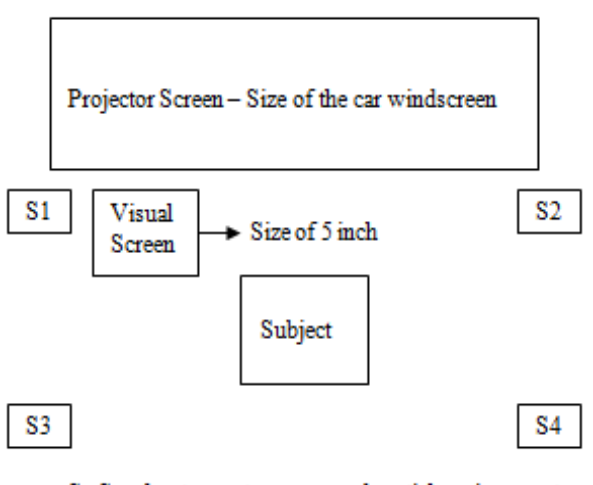

S - Speaker to create a surround spatial environment.

Fig. 7: Experimental layout 
Set 2: In set 2, a silence period exists between the ercons. The silence period's length changes according to the notification period as illustrated in Fig. 3 and 4. At a lower notification level, the length of the earcon is short and the length of the silence period is long between earcons. As it gets to a higher level of notification, the length of the silence period reduces and the length of the earcon increases. At the highest level of notification, the earcon's length and intensity is increased to alert the subject and there is a silence period between the earcons.

Set 3: In set 3, the earcons' attributes do not change, but the silence period's distance changes. The silence period's distance reduces as it goes to a higher notification as illustrated in Fig. 5 and 6. This changing attribute is variable and dependent on the distance.

Set 4: Description: Set 4 is the hybrid of set 1 and set 3 . It is a compound earcon that consists of a base earcon and silence periods. In set 4 , the amplitude of the base earcon and the length of the silence period changes according to the distance attribute. The amplitude of the base earcon will increase and the silence period will reduce as it goes to a higher notification level as illustrated in Fig. 7. Therefore, set 4 is flexible and noticeable because of its variable features.

\section{MATERIALS AND METHODS}

Auditory Lab Experiment aims at the subjects (driver)'s ability at recognizing and memorizing the auditory icons/earcons that represent certain functionalities of the DAS. The driving experiments involve the use of computer based vehicle controls (steering/pedals/panels) and a driving simulator to create a real-time driving environment (Weinberg and Harsham, 2009). The subject is supposed to drive in a computer-based driving simulator through a series of roads that includes a few junctions/traffic lights in an urban traffic condition. Before the experiment, the subject is given 15 minutes to test drive freely in the driving simulator. The subject does not know the route of the driving course. The subjects would not drive on the same route more than once (different routes and driving conditions). Therefore, these experiments are not repeated to ensure maximum dependability of the driver on the DAS (Chan et al., 2010). While driving, questions based on the earlier reading material will be posed to the driver that will later produce a situation where the driver is talking to passengers in the vehicle while driving based on the direction and guidance (simulating cognitive load) from DAS (Iqbal et al., 2010). Total number of subjects: 25 .

\section{RESULTS AND DISCUSSION}

In the driving experiments, 2 evaluation parameters were used: earcon recognition and number of correct turnings. In the earcon recognition process, the subjects are required to identify the set and level of notification of each earcon (Wesley et al., 2010). Two random earcon from each set were presented to the subjects ( $2 \times 4$ sets-total of 8 earcons in each experiment). Besides that, each set were used to provide navigational guide during each experiment (total of 4 set/experiments). The results of these experiments are shown Fig. 8.

The subjects were able to perform all correct turning based on the navigational guidance for set 3 and 4. The subjects were also able to correctly identify all earcons from set 4 . This proves that the subjects are able to differentiate and recognize the attributes for set 4. The above results also show the learning abilities of the subjects towards set 4 . This is proven by the increase of the subject's performance after each attempt (Garzonis et al., 2009). The silence period improves the differentiation process between the attributes that comprises each individual earcons and the associated design rule. Therefore, the design principles for set 4 can be utilized and further applied to other DAS functionalities.

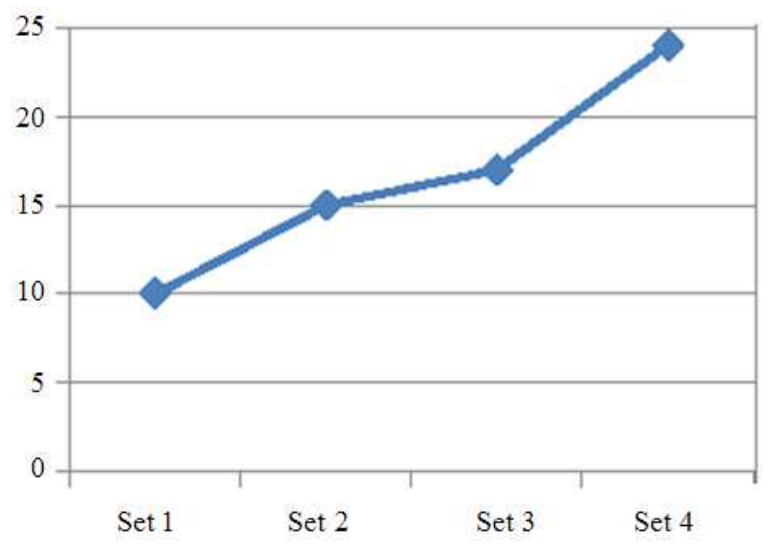

Fig. 8: Subject's performance evaluation towards correct earcon recognition (Set 1-4) 


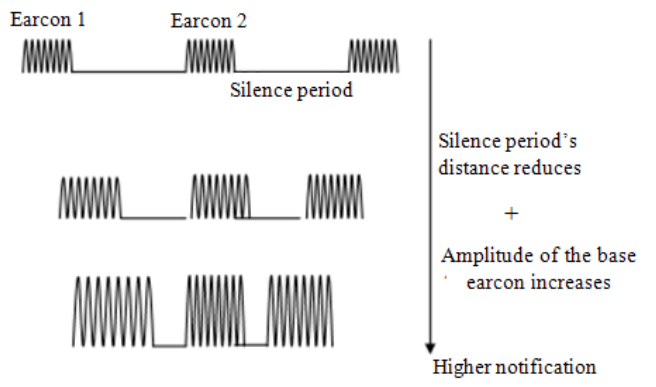

Fig. 9: Set 4 earcon design architecture
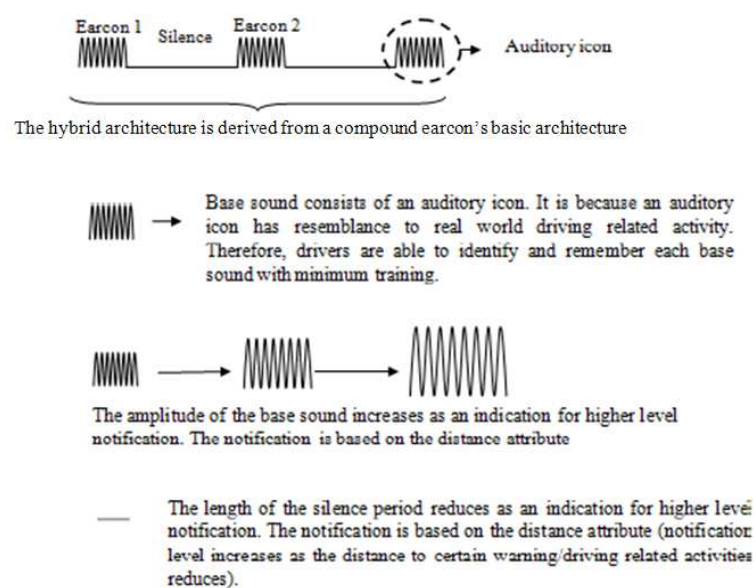

Fig. 10: Hybrid earcon design principles

\section{CONCLUSION}

In this study a holistic approach for information mapping (visual into non-speech based interaction) and presentation is presented. It outlines a set of hybrid design principles that integrates auditory icons with earcons to map and present real-time driving related data from a visual to a non-speech auditory interface. Figure 9 summarizes the design principles of the set 4's hybrid architecture.

As for future research direction, further interaction mapping between the overall functionalities of DAS and the hybrid auditory principles need to be carried to ensure its effectiveness for in-vehicle driving environment (Fig. 10). The novel contribution of this research can be used as a guideline for future application of auditory based interface for DAS.

\section{ACKNOWLEDGEMENT}

The researcher would like to thank the Malaysian Ministry of Science, Technology and Environment (MOSTE) for the research project's funding.

\section{REFERENCES}

Cao, Y., A. Mahr, S. Castronovo, M.E. Theune and C. Stahl et al., 2010. Local danger warnings for drivers: The effect of modality and level of assistance on driver reaction. Proceeding of the 14th International Conference on Intelligent user Interfaces, Feb. 7-10, ACM Press, New York, USA., $\quad$ pp: 239-248. 10.1145/1719970.1720004

Chan, E., A.K. Pradhan, A. Pollatsek, M.A. Knodler and D.L. Fisher, 2010. Are driving simulators effective tools for evaluating novice drivers' hazard anticipation, speed management and attention maintenance skills? Transport. Res. Part F: Traffic Psychol. Behav., 13: 343-353. DOI: 10.1016/j.trf.2010.04.001

Edlund, J., J. Gustafson, M. Heldner and A. Hjalmarsson, 2008. Towards human-like spoken dialogue systems. Speech Commun., 50: 630-645. DOI: $10.1016 /$ j.specom.2008.04.002

Fastrez, P. and J.B. Haué, 2008. Designing and evaluating driver support systems with the user in mind. Int. J. Hum.-Comput. Stud., 66: 125-131. DOI: $10.1016 /$ j.ijhcs.2008.01.001

Garzonis, S., S. Jones, T. Jay and E. O'Neill, 2009. Auditory icon and earcon mobile service notifications: Intuitiveness, learnability, memorability and preference. Proceedings of the 27th International Conference on Human Factors in Computing Systems, Apr. 4-9, ACM Press, New York, USA., pp: 1513-1522. DOI: 10.1145/1518701.1518932

Hoggan, E., R. Raisamo and S.A. Brewster, 2009. Mapping information to audio and tactile icons. Proceedings of the 2009 International Conference on Multimodal Interfaces, Nov. 2-4, ACM Press, New York, USA., pp: 327-334. DOI: 10.1145/1647314.1647382

Iqbal, S.T., Y.C. Ju and E. Horvitz, 2010. Cars, calls and cognition: Investigating driving and divided attention. Proceedings of the 28th International Conference on Human Factors in Computing Systems, Apr. 10-15, ACM Press, New York, USA., $\quad$ pp: $1281-1290 . \quad$ DOI: 10.1145/1753326.1753518

Kim, S.Y., J.K. Kang, S.Y. Oh, Y.W. Ryu and K. Kim et al., 2008. An intelligent and integrated driver assistance system for increased safety and convenience based on all-around sensing. J. Intell. Robot. Syst., 51: 261-287. DOI: 10.1007/s10846007-9187-0 
McGookin, D.K. and S.A. Brewster, 2004. Understanding concurrent earcons: Applying auditory scene analysis principles to concurrent earcon recognition. ACM Trans. Applied Percep., 1: 130-155. DOI: $10.1145 / 1024083.1024087$

Mohamad, D., B.M. Deros, D.A. Wahab, D.D.I. Daruis and A.R. Ismail, 2010. Integration of comfort into a driver's car seat design using image analysis. Am. J. Applied Sci., 7: 937-942. DOI: 10.3844/ajassp.2010.937.942

Sodnik, J., C. Dicke, S. Tomažič and M. Billinghurst, 2008. A user study of auditory versus visual interfaces for use while driving. Int. J. Hum.Comput. Stud., 66: 318-332. DOI: 10.1016/j.ijhcs.2007.11.001

Staubach, M., 2009. Factors correlated with traffic accidents as a basis for evaluating Advanced Driver Assistance Systems. Accid. Anal. Prevent., 41: 1025-1033. DOI: 10.1016/j.aap.2009.06.014

Winters, S.J. and D.B. Pisoni, 2006. Perception and comprehension of synthetic speech. Encyclop. Lang. Linguist., 1: 31-49.

Smith, A.C., J.S. Cook, J.M. Francioni, A. Hossain and M. Anwar et al., 2004. Nonvisual tool for navigating hierarchical structures. Proceedings of the 6th international ACM SIGACCESS Conference on Computers and Accessibility, Oct. 18-20, ACM Press, Atlanta, GA., USA., pp: 133-139. DOI: $10.1145 / 1028630.1028654$
Weinberg, G. and B. Harsham, 2009. Developing a low-cost driving simulator for the evaluation of invehicle technologies. Proceedings of the 1st International Conference on Automotive User Interfaces and Interactive Vehicular Applications, Sept. 21-22, ACM Press, New York, USA., pp: 51-54. DOI: $10.1145 / 1620509.1620519$

Wesley, A., D. Shastri and I. Pavlidis, 2010. A novel method to monitor driver's distractions. Proceedings of the 28th of the international conference extended abstracts on Human factors in computing systems, Apr. 10-15, ACM Press, New York, USA., pp: 4273-427. DOI: 10.1145/1753846.1754138

Yalla, P. and B.N. Walker, 2008. Advanced auditory menus: design and evaluation of auditory scroll bars. Proceedings of the 10th International ACM SIGACCESS Conference on Computers and Accessibility, Oct. 13-15, ACM Press, New York, USA., pp: 105-112. DOI: $10.1145 / 1414471.1414492$ 